\title{
DEEP-SEA ENVIRONMENTS IN THE ABSENCE OF POLAR ICE CAPS: THE CASE OF THE EARLY EOCENE
}

THOMAS, Ellen, Center for the Study of Global Change, Yale University, P.O. Box 208109, New Haven, CT 06520-8109, and Dept. of E\&ES, Wesleyan University, Middletown CT 06459-0139

In the early Eocene, the warmest period of the Cenozoic, high-latitude surface and global deep ocean waters were warmer than today by $10-12^{\circ} \mathrm{C}$. Tropical surface waters were slightly cooler than today, so that latitudinal thermal gradients were shallow. Climate modelers can not explain how to achieve the heat transport required to warm the poles at such shallow temperature gradients. The heat could possibly be transported by deep ocean waters, if subtropical surface waters reached a high salinity as a result of strong evaporation, became dense enough to fill the deep ocean basins, and flowed polewards. Carbon isotope data, however, do not unequivocally support such a circulation pattern. Benthic foraminifera have been said to reflect the oxygen content of waters in which they live, so that they could give information on patterns of deep-water circulation because warm deep waters can take up less oxygen in their source region than modern deep waters which exchange oxygen with the atmosphere at low temperatures; in addition, deep waters lose oxygen during their travel along the sea floor. It is, however, complex to interpret faunal patterns, and many more data sets at high time-resolution are needed. First, low-oxygen environments in the present oceans are usually associated with high organic fluxes, so that benthic assemblages may reflect a high supply of organic matter (food) rather than the low oxygen content. Second, deep-sea benthic foraminifera suffered their largest extinction of the last 90 million years in the latest Paleocene, so that early Eocene faunas may not have been in equilibrium with their environment. At the time of extinction global deep waters and high latitude surface waters warmed by $3-4^{\circ} \mathrm{C}$ within a few thousand years, and latitudinal temperature gradients became even shallower. The high temperatures persisted for about $50 \mathrm{kyr}$, during which faunas were low diversity and high dominance, commonly contained small, thin-walled taxa morphologically similar to Recent opportunistic taxa, but varied regionally. Faunal data suggest that along continental margins (especially Tethys and the Pacific) oxygen decreased or productivity increased, and data on sediments support increased delivery of organic matter to the sea floor. Increased productivity might have been fueled by increased run-off from land carrying nutrients produced by increased weathering. In the open Pacific, faunal data suggest increased delivery of organic matter or lowered oxygen, at a time when planktonic foraminifera suggest decreased productivity. This contradiction might be resolved if the benthics reflected either low oxygen conditions or arrival of more organic matter on the sea floor because of less oxidation, even at lowered productivity. In the southern Atlantic benthic faunal data suggest lowered productivity or increased oxygen contents; Indian ocean faunas vary, suggesting the presence of both oxygenated and less oxygenated water masses. The benthic faunas do thus not support the existence of deep oceans wholly dominated by warm salty waters even during the $50 \mathrm{kyr}$ interval after the extinction, when deep-water temperatures were at their maximum and such warm saline deep waters may have reached their highest volume. We do not have enough highresolution data to determine whether there was just one of these intervals, and isotope data suggest that there might have been more. Possibly, the high overall temperatures of the early Eocene reflect the average of overall high temperatures and superimposed 50 $100 \mathrm{kyr}$ intervals of extremely high temperatures and very low latitudinal sea surface temperature gradients, during which the deep oceans were dominated but not completely filled by waters derived from subtropical latitudes. 